\title{
Inhibitory Effect of Dorsal Cut of Hypothalamus on Ovulation Delayed by Pentobarbital in Female Rats
}

\author{
Miho WATANABE ${ }^{1 \#)}$ and Korehito YAMANOUCHI') \\ 1) Neuroendocrinology, Department of Basic Human Sciences, School of Human Sciences, \\ Waseda University, 2-579-15, Mikajima, Tokorozawa, Saitama 359-1192, Japan \\ \#Present: Department of Physiology, Nippon Medical School, 1-1-5, Sendagi, Bunkyo, Tokyo \\ 113-8602, Japan
}

\begin{abstract}
To clarify the role of the extrahypothalamic signals to the hypothalamus in regulating ovulation, the effect of interruption of the dorsal inputs of the hypothalamus on delayed ovulation induced by the treatment with pentobarbital (PB) was examined in female rats. A posterior half-circle horizontal cut at the dorsal of the hypothalamus (PDC) was made and spontaneous ovulation or ovulation delayed by PB were observed. When PDC was performed at 10:00-11:30 h on the day of proestrus, ovulation occurred normally the next morning in all rats. Treatment with PB at 16:00h on the day of proestrus, but not at 13:00 h, induced one-day-delayed ovulation in most rats without brain surgery. In contrast, ovulation was seen normally on estrus in $60.0 \%$ of PDC females, when treated with PB at 16:00 h. However when PB was injected at 13:00 h, ovulation was delayed one day in 88.9\% of PDC females. Twenty days after making PDC, delayed ovulation was not induced by PB at 16:00 h in $54.5 \%$ of rats. These results suggest the possibility that PDC advances the effective period in which PB can cause delayed ovulation. Furthermore, the effect of the PDC continues for at least 20 days after the operation. Thus, dorsal inputs to the hypothalamus may be concerned with a control mechanism of the critical period for triggering of ovulation in female rats.
\end{abstract}

Key words: Delayed ovulation, Pentobarbital, Extrahypothalamic influence, Critical period, Cuts, Rat

(J. Reprod. Dev. 47: 253-258, 2001)

D vulation is known to be delayed one day by anaesthetizing the brain, by injection with pentobarbital (PB) for example, in female rats [1]. The period during which $\mathrm{PB}$ is effective at delaying ovulation is the early evening of proestrus, because injection of $\mathrm{PB}$ in this period delays ovulation but when $\mathrm{PB}$ is injected in the morning or late evening of proestrus there is no delay [2]. In this critical period, an ovulation-triggering mechanism in the brain is thought to start operating [3]. Following this period, a GnRH-surge occurs. Since, increase of GnRH mRNA-expressing cells in the preoptic area (POA) on the evening of the proestrus is

Accepted for publication: June 25, 2001

Correspondence: K. Yamanouchi

blocked by PB [4], and electrical stimulation of this nucleus recovered ovulation suppressed by PB [5], it is assumed that a GnRH releasing signal is released from the cyclic center of ovulation in the POA in the critical period.

The critical period is not rigid, because change of daily illumination time can move it. Under daily illumination from 5:00 to 19:00, the critical period of rats is 14:00-16:00 [1], and LH-surge is seen from 17:00 to 19:00 [6], but under illumination from 7:00 to 21:00, the LH-surge occurs from 19:00 to 21:00 [7]. A constant light condition induces anovulatory syndrome [8]. Thus, the critical period for ovulation is dependent on the length of illumination time. The suprachiasmatic nucleus, 
which receives fibers from the retina and controls circadian rhythm, is involved in the mechanisms which transduce light signals to the ovulation regulating system, because restricted lesions of this nucleus suppress ovulation in female rats [9].

The limbic area also exerts important influences on regulation of ovulation. The amygdala [11-13] and the hippocampus [14] play roles in modification of the ovulatory cycle. In the finding of Schuiling and Van Rees [15], dorsal inputs of the hypothalamus modified the critical period for ovulation. In this experiment, to confirm their results and to investigate further the role of dorsal inputs of the hypothalamus in regulating ovulation, a posterior half-circle horizontal cut was made at the dorsal of the hypothalamus and delayed ovulation induced by PB was examined in female rats.

\section{Materials and Methods}

\section{Animals}

Female Wistar rats were housed under controlled a photoperiod (14L:10D, lights on from 07:00 to 21:00 h) and temperature (23-25 C). The rats received food and water ad libitum. Vaginal smears were taken throughout the experimental period and only rats exhibiting 2 or more consecutive regular 4-day estrous cycle were used. This experiment was done according to the Guideline for the Care and Use of Laboratory Animals in the Human Science Department of Waseda University.

\section{Ova counting}

The ovulatory condition was assessed by counting ova in unilateral oviducts during the estrus (E) and diestrus I (DI) in the same animal [see 16]. On the morning of $E$, the left oviduct was dissected under ether anesthesia and ova in the oviduct were counted under a microscope. Next morning on DI, animals were sacrificed by overexposure to ether and ova in the remaining oviduct (right side) were checked.

\section{Brain surgery}

To investigate the role of the dorsal afferents of the POA-medial basal hypothalamus passing posterior to the anterior commissure in the ovulation delaying mechanism activated by $\mathrm{PB}, \mathrm{a}$ posterior half-circle horizontal cut (PDC) at the dorsal of the hypothalamus (Fig. 1) was made on the proestrous $(\mathrm{P})$ morning (10:00-11:30 h).

In the brain surgery under ether anesthesia, 39 rats were fixed to a stereotaxic instrument with an incisor bar set at $5 \mathrm{~mm}$ below the interaural line. A L-shaped Halász knife with a horizontal blade of 2 $\mathrm{mm}$ directed posteriorly was lowered $7.0 \mathrm{~mm}$ from the bregma level to a point where the blade tip was $2.4 \mathrm{~mm}$ posterior to the bregma on the midline and was rotated posteriorly $90^{\circ}$ to the left and right. In 9 females, the sham operated group, the knife was lowered to the same level as the PDC group without rotation. Twenty-four females without brain surgery were prepared as intact or control groups.

\section{PB injection}

In order to investigate the effect of PDC on spontaneous ovulation, ovulation was checked by the methods described above after PDC with no treatment in 9 females (PDC group). As an intact control, ovulation was observed on E and DI in 8 females without brain surgery (intact group).

PB (30 mg/kg B.W., Nembutal, DAINABOT) was injected intraperitoneally at 16:00 $\mathrm{h}$ or 13:00 $\mathrm{h}$ on $\mathrm{P}$ on the same day as brain surgery, because a preliminary experiment showed that delayed ovulation occurred when PB is injected at 16:00 h but not at 15:00 h under our light regime. Nine and 7 females with no brain surgery were injected with $\mathrm{PB}$ at 16:00 $\mathrm{h}$ and13:00 $\mathrm{h}$ respectively. In 10 and 9 PDC females, PB was injected at 16:00 $\mathrm{h}$ and 13:00 $h$, respectively (PDC+PB group).

In addition, $\mathrm{PB}$ was injected at 16:00h on $\mathrm{P}$ in 11 PDC females to investigate the chronic effect of PDC on ovulation delayed by PB, after the reappearance of 5 consecutive normal 4-day vaginal estrous cycles (about 20 days).

Ova in the unilateral oviducts were counted on $\mathrm{E}$ and DI by the methods described above. All animals were sacrificed on the second day of ova counting by overdose of ether anesthesia.

\section{Histological examination}

To determine the precise localization of the cut, a histological examination of the brain was performed. Each brain was removed and fixed in $10 \%$ formalin solution and $100-\mu \mathrm{m}$ frozen sections were made and stained with cresyl fast violet. The location of the cut was determined according to 


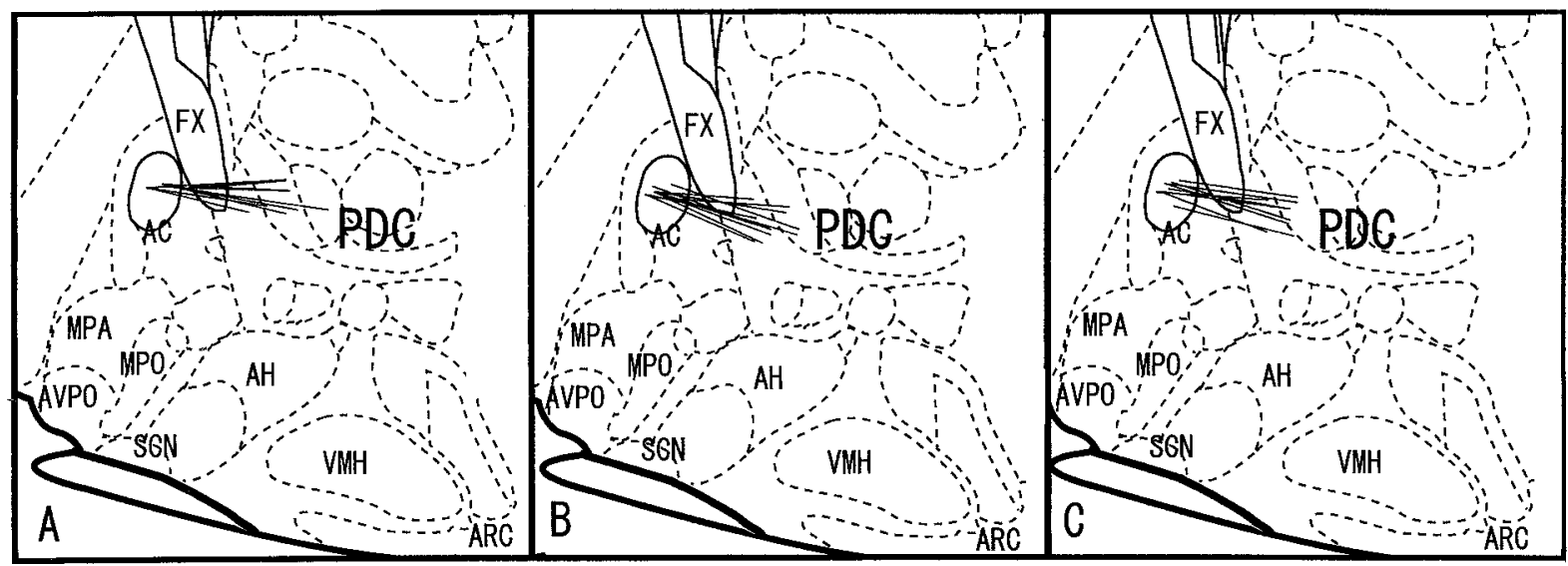

Fig. 1. Sagittal section of the brain showing the line of PDC in the PDC+PB (16:00) (A), cPDC+PB (B) and PDC+PB (13:00) (C) groups. AC: anterior commissure; $\mathrm{AH}$ : anterior hypothalamic nucleus; ARC: arcuate hypothalamic nucleus; AVPO: anteroventral preoptic nucleus; CC: corpus callosum; FX: fornix; MPA: medial preoptic area; MPO: medial preoptic nucleus; SCN: suprachiasmatic nucleus; VMH: ventromedial hypothalamic nucleus.

Table 1. Effects of posterodorsal horizontal cut (PDC) of the hypothalamus on spontaneous or ovulation delayed by PB

\begin{tabular}{|c|c|c|c|c|c|c|c|c|c|c|}
\hline \multirow[t]{2}{*}{ Groups } & \multirow{2}{*}{$\begin{array}{l}\text { No. } \\
\text { of Rats }\end{array}$} & \multicolumn{5}{|c|}{ Day 1 (expected Estrus) } & \multicolumn{3}{|c|}{ Day 2 (expected Diestrus I) } & \multirow[b]{2}{*}{ Body Weight (g) } \\
\hline & & $\begin{array}{c}\text { No. of Rats } \\
\text { ovulating }\end{array}$ & $\%$ & $\begin{array}{l}\text { No. of ova } \\
\text { (Mean } \pm \text { S.E.) }\end{array}$ & $\begin{array}{c}\text { Incidence of } \\
\text { Vaginal Estrus }\end{array}$ & $\begin{array}{c}\text { No. of Rats } \\
\text { ovulating }\end{array}$ & $\%$ & $\begin{array}{c}\text { No. of ova } \\
\text { (Mean } \pm \text { S.E.) }\end{array}$ & $\begin{array}{c}\text { Incidence of } \\
\text { Vaginal Estrus }\end{array}$ & \\
\hline Intact & 8 & $8 / 8$ & $(100)$ & $5.8 \pm 0.6$ & $8 / 8$ & $0 / 8$ & (0) & - & $0 / 8$ & $291 \pm 10$ \\
\hline PDC & 9 & $8 / 9$ & $(88.9)$ & $6.6 \pm 0.5$ & $9 / 9$ & $1 / 9$ & $(11.1)$ & 7 & $1 / 9$ & $257 \pm 10$ \\
\hline \multicolumn{11}{|c|}{ PB administration at $16: 00$} \\
\hline Control & 9 & $0 / 9$ & (0) & - & $9 / 9$ & $9 / 9$ & $(100)$ & $5.8 \pm 0.7$ & $9 / 9$ & $256 \pm 8$ \\
\hline Sham & 9 & $1 / 9$ & (11.1) & 4 & $9 / 9$ & $6 / 9$ & $(66.7)$ & $6.2 \pm 1.2$ & $6 / 9$ & $276 \pm 5$ \\
\hline PDC & 10 & $6 / 10^{*}$ & $(60.0)$ & $7.3 \pm 1.2$ & $10 / 10$ & $3 / 10^{*}$ & $(30.0)$ & $6.7 \pm 1.7$ & $4 / 10$ & $248 \pm 8$ \\
\hline cPDC & 11 & $6 / 11^{*}$ & $(54.5)$ & $6.2 \pm 1.1$ & $11 / 11$ & $5 / 11^{*}$ & $(45.5)$ & $6.6 \pm 0.5$ & $5 / 11$ & $306 \pm 9$ \\
\hline \multicolumn{11}{|c|}{ PB administration at 13:00 } \\
\hline Control & 7 & $6 / 7$ & (85.7) & $7.5 \pm 0.7$ & $7 / 7$ & $1 / 7$ & $(14.3)$ & 11 & $1 / 7$ & $266 \pm 7$ \\
\hline PDC & 9 & $1 / 9^{* *}$ & (11.1) & 3 & $9 / 9$ & $8 / 9^{* *}$ & $(88.9)$ & $9.4 \pm 1.4$ & $8 / 9$ & $253 \pm 9$ \\
\hline
\end{tabular}

${ }^{*} \mathrm{P}<0.01$ vs Control (PB at 16:00), ** $\mathrm{P}<0.01$ vs Control $(\mathrm{PB}$ at 13:00).

Paxinos and Watson [17].

The data regarding the incidence of ovulation was evaluated by means of the $\chi^{2}$-test and the number of ova in each group was analyzed by unpaired Student's t-test.

\section{Results}

In the intact group, ova were found in all animals on $\mathrm{E}$ and the mean number of ova was $5.8 \pm 0.6$ (Table 1). As well as the intact group, most PDC rats without $\mathrm{PB}$ showed ovulation on $\mathrm{E}$ and the mean number of ova was almost the same as that in the intact group.

When PB was injected at 16:00 h, ovulation did not occur on $\mathrm{E}$ but ova were found on DI in all control rats. In the sham group, all rats with $\mathrm{PB}$ except 1 showed no ovulation on E, but 6 out of 9 rats ovulated on DI. Two sham rats had no ovulation during E and DI. All rats that ovulated on DI showed vaginal cornification in 2 consecutive days in the control and sham groups. In contrast, when PB was injected at 16:00 h, 6 out of 10 PDC rats ovulated on the $E$ and the mean number of ova was comparable to those of the control and sham groups. Three PDC+PB rats ovulated on DI, and no ovulation was observed in one PDC rat. In the 
chronic PDC + PB group, 6 out of 11 rats also ovulated on $\mathrm{E}$ and 5 rats showed ovulation on DI. When PB was injected at 13:00 h, 6 out of 7 control rats ovulated normally on $\mathrm{E}$. In contrast, in the $\mathrm{PDC}+\mathrm{PB}$ group, ovulation was observed in only 1 rat on $\mathrm{E}$ and the remaining 8 rats ovulated on DI. Vaginal cornification was observed 2 consective days in the rats ovulating on the DI. In rats ovulating on E, vaginal smear showed a diestrous condition in DI.

In the histological examination, PDC was located at the level of the anterior commissure (Fig. 1). The cuts were extended from the posterior end of the anterior commissure to the area including the ventral part of the nucleus reuniens thalami, dorsal to the paraventricular hypothalamus nucleus. In the surface of the cortex and in the triangular septal nucleus, traces of the lowering knife were seen. Differences in the location of the cut between animals which showed delayed ovulation and animals with no delayed ovulation after PB were not detected clearly.

\section{Discussion}

In the present experiment, ovulation occurred normally on E, even when PDC was performed on the morning of $\mathrm{P}$ in 4-day estrous cycle rats. This indicates that PDC in the morning of the day before ovulation has no effect on induction of ovulation. When PB was injected at 16:00 h, ovulation was delayed one day in all control rats. This is consistent with many reports that $\mathrm{PB}$ injection before the critical period for ovulation causes oneday-delayed ovulation [1]. In contrast, $60 \%$ of PDC females showed normal ovulation on E. This result agreed with a report that PDC cancels the effect of PB on ovulation [15]. However, in $40 \%$ of animals, PDC did not cancel the PB effect. Although the reason for the absence of PDC effect in these animals is not known, a possible explanation is that the quantity of fibers controlling ovulation injured by the half-circle cut of PDC was not enough. Futhermore, no ovulation in 3 rats of the sham and PDC groups may have been caused by the stress of acute brain surgery. In the case of $\mathrm{PB}$ injection at 13:00 h, control females showed normal ovulation on the morning of E but ovulation in $89 \%$ of PDC females was delayed by one day. This suggests that $\mathrm{PB}$ at 13:00 $\mathrm{h}$ is effective at inducing delayed ovulation when PDC is performed. Because anesthetization of the brain during the critical period causes delayed ovulation [3], it can be said that PDC advances the critical period. Furthermore, the advancement of the critical period by PDC continued for more than 20 days. Thus, the neuronal fibers, which were cut by PDC, may play an important role in determining the time schedule of the critical period for ovulation in female rats. In our laboratory, a preovulatory LH-surge was determined to occur from 19:00 to 21:00 [7]. Since there is a possibility that this time also advances in PDC females, a hormonal assay is necessary to clarify this point.

It can be assumed that limbic projections are involved in the critical period regulating mechanisms. Hippocampal efferents have been shown to leave the ventral subiculum, presubiculum and parasubiculum and project to the POA, arcuate nucleus, ventromedial nucleus, dorsomedial nucleus and ventral premammillary nucleus via the fornix and medial corticohypothalamic tract [18]. Electrical or electrochemical stimulation of the dorsal and ventral hippocampus on $\mathrm{P}$ inhibits the increase of LH and FSH release and ovulation [14]. The blockade of ovulation by electrical stimulation of the ventral hippocampus was overcome by the transection of the medial corticohypothalamic tract [19]. The multiple unit activity (MUA) of the arcuate nucleus was increased by stimulation of the ventral hippocampus and this increase was also prevented by transection of the medial corticohypothalamic tract [20]. When the fornix was transeced on DII, ovulation was advanced one day in rats with 5-day estrous cycles [21]. The MUA of the hippocampus and fornix started to decrease on the day of DII corresponding with the increase of estrogen secretion from the ovary [22]. These facts indicate that the hippocampus plays an inhibitory role in regulation of ovulation. Thus, it can be speculated that PDC transected the fibers from the hippocampus resulting in disruption of ovulation delayed by PB.

On the other hand, electrical or electrochemical stimulation of the lateral amygdala on P inhibits the increase of LH and FSH release and ovulation [11, 13]. The MUA of the lateral amygdala started to decrease on DII and continued into the afternoon of $\mathrm{P}$ [21]. The lateral amygdala contains large amounts of estrogen receptors [23, 24]. These 
reports indicate that the lateral amygdala exerts an inhibitory influence on the regulation of ovulation. As well as the hippocampus, the amygdala may also have contributed to the shifting of the effective period of PB in PDC in this experiment.

The condition of illumination is an important factor in maintaining normal cyclic ovulation, because a persistent light condition induces anovulation in female rats [8]. The suprachiasmatic nucleus (SCN) is well known to produce signals for 24-h rhythm in the brain [25], and destruction of the SCN disturbs ovulation $[9,26]$. There is a neural connection between the limbic area and the SCN [27]. Based on the report showing that PB blocks both light-induced phase shifts and photic induction of Fos in the suprachiasmatic nucleus [28], we propose that PB inhibits the transmission of photic information before it reaches the circadian oscillator within the suprachiasmatic nucleus. It is possible to say that mechanisms for ovulation delayed by PB involve the SCN connecting with the limbic mechanism.

PB enhances activity of the GABA neuronal system $[29,30]$. The GABA neuronal system is thought to be involved in the regulatory system for ovarian cyclicity and LH secretion $[6,31]$. GABA receptors are found in the neurons of the POA [32]. The SCN also contains a GABA receptor system [33]. Infusion of $\mathrm{GABA}_{\mathrm{A}}$ receptor antagonist, bicucullin, has been reported to advance the timing of the LH surge [31]. Pulsatile secretion of GnRH is thought to be an important factor in the precise control of LH secretion and the generator exists in the medial basal hypothalamus [34]. It has been reported that PB stimulates the activity of GnRH pulsatile secretion in proestrous [35]. However, endogenous GABA receptor activity has also been suggested as having a small contribution to the control of the pulse generator [36]. Thus, rather than the pulsatile secretion system, LH-surge control system in the POA including the suprachiasmatic nucleus involves the GABAergic system. The limbic area contains GABA neurons [37]. Although there is no direct evidence, the possibility can not be excluded that PDC disturbs GABAergic neural inputs to the LH-cyclic secretion center in the POA. Further studies are needed to elucidate this.

\section{Acknowledgement}

We wish to express our hearty thanks to Dr. S. Shibata of Waseda University for his valuable suggestions. This study was supported by a Grantin-Aid from the JSPS (11640669), grants for special research projects (2001A-611) and grants from AR Center for Human Sciences of Waseda University and the Promotion and Mutual Aid Corporation for the Private Schools of Japan to K.Y.

\section{References}

1. Everett JW, Sawer CH. A 24-hour periodicity in the 'LH-release apparatus' of female rats, disclosed by barbiturate sedation. Endocrinology 1950; 47: 198218.

2. Freeman ME. The neuroendocrine control of the ovarian cycle of the rat. In: Knobil E, Neill JD (eds.), The Physiology of Reproduction. New York: Raven 1994; 613-658.

3. Schwartz NB. A model for the regulation of ovulation in the rat. Recent prog Hormone Res 1969; 25: 1-55.

4. Park OK, Gugneja S, Mayo KE. Gonadotropinreleasing hormone gene expression during the rat estrous cycle: Effects of pentobarbital and ovarian steroids. Endocrinology 1990; 127: 365-372.

5. Terasawa EI, Wiegand SJ, Bridwon WE. A role for medial preoptic nucleus on afternoon of proestrus in female rats. Am J Physiol 1980; 238: E533-539.

6. Herbison AE, Dyer RG. Effect on luteinizing hormone secretion of GABA receptor modulation in the medial preoptic area at the time of proestrous luteinizing hormone surge. Neuroendocrinology 1991; 53: 317-320.

7. Maekawa F, Tsukahara S, Tsukamura H, Maeda KI, Yamanouchi K. Prevention of inhibitory effect of dorsal raphe nucleus lesions on ovulation and $\mathrm{LH}$ surge by 5 -HT $2 \mathrm{~A} / 2 \mathrm{C}$ receptor agonists in female rats. Neurosci Res 1999; 35: 291-298.

8. Hardy DF. The effect of constant light on the estrous cycle and behavior of the female rat. Physiol Behav 1970; 5: 421-425.

9. Wiegand SJ, Terasawa EI, Bridson WE, Goy RW. Effects of discrete lesions of preoptic and suprachiasmatic structures in the female rat. Neuroendocrinology, 1980; 31: 147-157.

10. Bagga N, Chhina GS, Mohan Kumar V, Singh B. Cholinergic activation of medial preoptic area by amygdala for ovulation in rat. Physiol Behav 1984; 32: 
$45-48$.

11. Carrillo AJ, Rabii J, Carrer HF, Sawyer CH. Modulation of the proestrous surge of luteinizig hormone by electrochemical stimulation of the amygdala and hippocampus in the unanesthetized rat. Brain Res 1977; 128: 81-92.

12. Velasco ME, Taleisnik $S$. Effects of the interruption of amygdaloid and hippocampal afferents to the medial hypothalamus on gonadotrophin release. $J$ Endocrinol 1971; 51: 41-55.

13. Kawakami M, Kimura F. Inhibition of ovulation in the rat by electrical stimulation of the lateral amygdala. Endocrinol Japon 1975; 22: 61-65.

14. Kawakami M, Kimura F, Kawagoe S. Cholinergic and serotonergic neural links and the inhibitory effects of hippocampus, lateral amygdala and central gray matter on gonadotropin release. Endocrinol Japon 1976; 23: 11-21.

15. Schuiling GA, Van Rees GP. Evidence of an extrahypothalamic inhibitory influence on the secretion of gonadotropins in the female rat. Neuroendocrinology 1974; 15: 73-78.

16. Watanabe M, Yamanouchi K. Suppression of spontaneous ovulation by interruption of dorsal input of hypothalamus at various timings during rat estrous cycle. J Reprod Dev 2000; 46: 39-45.

17. Paxinos G, Watson C. The Rat Brain in Stereotaxic Coordinates. 2nd ed, New York: Academic Press; 1986.

18. Canteras NS, Simerly RB, Swanson LW. Organization of projections from the medial nucleus of the amygdala: A PHAL study in the rat. J Comp Neurol 1995; 360: 213-245.

19. Velasco ME, Taleisnik S. Effect of hippocampal stimulation on the release of gonadotropin. Endocrinology 1969; 85: 1154-1159.

20. Gallo RV, Johnson JH, Goldman BD, Whitmoyer DI, Sawer CH. Effects of electrochemical stimulation of the ventral hippocampus on hypothalamic electrical activity and pituitary gonadotropin secretion in female rats. Endocrinology 1971; 89: 704713.

21. Kawakami M, Kimura F. Acute and chronic effects of the fornix section on cyclic gonadotropin secretion and ovulation in the rat. Endocrinol Japon 1975; 22: 43-48.

22. Kawakami M, Kimura F. Possible roles of CNS estrogen-neuron systems in the control of gonadotropin release. In: Stumpf WE, Grant LD (eds.), Anatomical Neuroendocrinology. S. Karger, 1975; 216-231.

23. Simerly RB, Chang C, Muramatsu M, Swanson LW. Distribution of androgen and estrogen receptor mRNA-containing cells in the rat brain: An in situ hybridization study. J Comp Neurol 1990; 294: 76-95.

24. Stumpf WE, Sar M, Keeger DA. Atras of estrogen target cells in rat brain. In: Stumpf WE, Grant LD (eds.), Anatomical Neuroendocrinology. S. Karger, 1975; 104-119.

25. Inouye $\mathbf{S T}$, Shibata $\mathbf{S}$. Neurochemical organization of circadian rhythm in the suprachiasmatic nucleus. Neurosci Res 1994; 20: 109-130.

26. Brown-Grant K, Raisman G. Abnormalities in reproductive function associated with the destruction of the suprachiasmatic nuclei in female rats. Proc R Soc Lond B Biol Sci 1977; 198: 279-296.

27. Pickard GE. The afferent connections of the suprachiasmatic nucleus of the golden hamster with emphasis on the retinohypothalamic projection. J Comp Neurol 1982; 211: 65-83.

28. Colwell CS, Kaufman CM, Menaker M, Ralph MR. Light-induced phase shifts and Fos expression in the hamster circadian system: the effects of anesthetics. J Biol Rhythms 1993; 8: 179-188.

29. Sieghart W. GABA receptors: ligand-gated $\mathrm{Cl}^{-}$ion channels modulated by multiple drug-binding sites. TiPS 1992; 13: 446-450.

30. Schulz DW, MacDonald RL. Barbiturate enhancement of GABA-mediated inhibition and activation of chloride ion conductance. Brain Res 1981; 209: 177-188.

31. Kimura F, Jinnai K. Bicuculline infusions advance the timing of luteinizing hormone surge in proestrous rats: comparisons with naloxone effects. Horm Behav 1994; 28: 424-430.

32. Toyama M, Takatsuji K (eds.) Atlas of Neuroactive Substances and Their Receptors in the Rat. Oxford: Oxford University Press, 1998.

33. Shinohara K, Hiruma H, Funabashi T, Kimura F. GABAergic modulation of gap junction communication in slice cultures of the rat suprachiasmatic nucleus. Neurosci 2000; 96: 591-596.

34. Maeda K-I, Tsukamura H, Ohkura S, Yokoyama A. Neuroendocrine mechanism regulating the pulsatile luteinizing hormone secretion. In: Yokoyama A (ed.), Brain Control of the Reproductive system. Tokyo: Japan Sci. Soc. Press 1992; 119-139.

35. Funabashi T, Jinnai K, Sano A, Shinohara K, Kimura F. Pentobarbital stimulates the activity of the GnRH pulse generator interacting with opioid neurons in rats in proestrus. Psychoneuroendocrinology 2000; 25, 277-287.

36. Kimura F, Sano A, Hiruma H, Funabashi T. Effects of gamma-aminobutyric acid A receptor antagonist, bicuculline, on the electrical activity of luteininizing hormone-releasing hormone pulse generator in the ovariectomized rat. Neuroendocrinology 1993; 57: 605-614.

37. Muganishi E, Oertel WH. An atlas of the distribution of GABAergic neurons and terminals in the rat. In: Bjorklund A, Hokfelt T (eds.), Handbook of Chemical Neuroanatomy. Elsevier, 1985; 4: 436608. 